\title{
On Solving Hyperbolic Trajectory Using New Predictor-Corrector Quadrature Algorithms
}

\author{
Mohammed S. Rasheed*
}

Received 31, March, 2013

Accepted 13, August, 2013

\begin{abstract}
:
In this Paper, we proposed two new predictor corrector methods for solving Kepler's equation in hyperbolic case using quadrature formula which plays an important and significant rule in the evaluation of the integrals. The two procedures are developed that, in two or three iterations, solve the hyperbolic orbit equation in a very efficient manner, and to an accuracy that proves to be always better than $10^{-15}$. The solution is examined with $e \in[1.5,6]$ and $M_{k} \in[0.5,6]$ with grid size $\Delta M_{h}=\Delta e=0.5$, using the first guesses hyperbolic eccentric anomaly is $H_{0}=\ln \left(\frac{2 M_{h}}{\theta}+1.5\right)$ and $H_{0}=\ln \left(\frac{2 M_{h}}{\theta}+2\right)$, where $e$ is the eccentricity and $M_{h}$ is the hyperbolic mean anomaly.
\end{abstract}

\section{Key words: Hyperbolic trajectory, Hyperbolic eccentric anomaly, Quadrature rule, Predictor-corrector method.}

\section{Introduction:}

Many instances of hyperbolic orbits occur in the solar system and recently, among the artificial satellites, lunar and solar probes. Moreover, in some cases of orbit determination for an elliptic orbit, it may very well happen that during the solution process (usually iteration), the eccentricity $\mathrm{e}$ becomes greater than unity and the orbit becomes hyperbolic. Also, in the interplanetary transfer, the escape from the departure planet and the capture by the target planet involves hyperbolic orbits. On the other hand, in orbit determination of visual binaries provisional hyperbolic orbits are used to represent the periastron section of high-eccentricity orbits of long and indeterminate period. In fact, we should handle hyperbolic orbits frequently when integrating a perturbed motion with the initial condition of nearly parabolic orbits [1$3]$.

In a nutshell, the so-called kepler's problem consists of determining the radial and angular coordinates, rand, respectively of an object about the sun as a function of time. For the case of a hyperbolic orbit, characterized by e $>1$, we have [4]

e $\sinh H-H=M_{h}$

$1 \leq \mathrm{e}<\infty ; 0 \leq \mathrm{M}_{\mathrm{h}} \leq \infty$

where e (eccentricity) and $\mathrm{M}_{\mathrm{h}}$ (hyperbolic mean anomaly) are assumed to be known and $\mathrm{H}$ (hyperbolic eccentric anomaly) is to be determined. Eq. (1) is a transcendental equation and analytical methods for solving such equations are difficult or almost non-existent. Therefore; it is only possible to obtain approximate solutions by numerical techniques based on iteration procedures. Burkarat [5] considered starting values for the iteration solution of Kepler's equation for hyperbolic orbits, eq. (2) and for generalized versions of the equation, while; Gooding [6] developed a procedure to solve the hyperbolic Kepler's equation. An efficient iterative method of arbitrary integer order of convergence $\geq 2$ was established by

\footnotetext{
*Applied Sciences Department, University of Technology.
} 
Sharaf [7] for solving the hyperbolic form of Kepler's equation, error formulae for solving a hyperbolic form of Kepler's equation using the Homotopy method presented by [8]. Other works concerning Kepler's equation for hyperbolic case can be found in [9-12]. In this paper, we suggest two new algorithms by using Simpson's $\frac{1}{a}$ rule. This method is an implicit type method. To implement this, we will use the Newton and the Halley methods, as a predictor method and then use this new method as a corrector method. A comparison between this new method with that of Newton method and the implicit method in [13] is given to show the performance of the new methods.

\section{Two New Predictor- Corrector Methods for Solving Hyperbolic Equation}

Now, we suggest the following twostep predictor-corrector type iterative methods for solving Kepler's Equation in hyperbolic orbit equation, eq. (1)

Rewrite eq. (1) as

$f(H)=e \sin H-H-M_{h}=0$,

$1 \leq e<\infty ; 0 \leq M_{h}<\infty$

Then

$\mathrm{f}(\mathrm{H})=\mathrm{f}\left(\mathrm{H}_{\mathrm{n}}\right)+\int_{\mathrm{H}_{\mathrm{n}}}^{\mathrm{H}} \mathrm{f}(\mathrm{t}) \mathrm{dt}$

if we approximate $\int_{\mathrm{H}_{\mathrm{n}}}^{\mathrm{H}} \mathrm{f}(\mathrm{t}) \mathrm{dt}$ with the Simpson's $\frac{1}{a}$ quadrature formula, yields

$\int_{H_{n}}^{H} \hat{f}(t) d t=\frac{H-H_{n}}{6}\left[\hat{f}\left(H_{n}\right)+4 \hat{f}\left(\frac{H-H_{n}}{2}\right)+\hat{f}(H)\right]$

Put eq. (4) into eq. (3) to obtain

$\mathrm{f}(\mathrm{H})=\mathrm{f}\left(\mathrm{H}_{\mathrm{n}}\right)+\frac{\mathrm{H}-\mathrm{H}_{\mathrm{n}}}{6}\left[\mathrm{f}\left(\mathrm{H}_{\mathrm{n}}\right)+4 \hat{\mathrm{f}}\left(\frac{\mathrm{H}-\mathrm{H}_{\mathrm{n}}}{2}\right)+\mathrm{f}(\mathrm{H})\right]$

since, $\mathrm{f}(\mathrm{H})=0$, then

$H=\mathrm{H}_{\mathrm{n}}-\frac{6 \mathrm{f}\left(\mathrm{H}_{\mathrm{n}}\right)}{\mathrm{f}\left(\mathrm{H}_{\mathrm{n}}\right)+4 \mathrm{ff}\left(\frac{\left(\mathrm{H}-\mathrm{H}_{\mathrm{n}}\right.}{2}\right)+\mathrm{f}(\mathrm{H})}$
Using the predictor-corrector type technique, we suggest the following two-step method which is obtained by combining the Newton method to obtain algorithm (1).

Algorithm (1): for a given $\mathrm{H}_{0}$, compute the approximate solution $\mathrm{H}_{\mathrm{n}+1}$ by the iterative scheme

$\mathrm{H}_{\mathrm{n}+1}^{*}=\mathrm{H}_{\mathrm{n}}-\frac{\mathrm{f}\left(\mathrm{H}_{\mathrm{n}}\right)}{\mathrm{f( \textrm {H } _ { \mathrm { n } } )}}$

$H_{n+1}=H_{n}-\frac{6 f^{\left(H_{n}\right)}}{f\left(H_{n}\right)+4 f\left(\frac{H_{n}+H_{n+1}^{n}}{2}\right)+\mathrm{f}^{\prime}\left(H_{n+1}^{*}\right)}$,

$\mathrm{n}=0,1,2,3, \ldots$

In similar way, we will have algorithm (2), which our predictor is Halley method.

Algorithm (2): for a given $\mathrm{H}_{0}$, compute the approximate solution $\mathrm{H}_{\mathrm{n}+1}$ by the iterative scheme

$$
H_{n+1}^{*}=H_{n}-\frac{6 f\left(H_{n}\right) f\left(H_{n}\right)}{2\left(f\left(H_{n}\right)\right)^{2}-f\left(H_{n}\right) f^{v}\left(H_{n}\right)}
$$

$$
H_{n+1}=H_{n}-\frac{6 f^{\prime}\left(H_{n}\right)}{f\left(H_{n}\right)+4 f\left(\frac{H_{n}^{*}+H_{n+1}^{n}}{2}\right)+f\left(H_{n+1}^{*}\right)}
$$$$
\mathrm{n}=0,1,2,3, \ldots
$$

An efficient starting iteration $\mathrm{H}_{0}$ can be obtained by substitution for $(\sinh H)$, eq. (1) can be written as [5],

$e\left(\frac{\exp [H]-\exp [-H]}{2}\right)-H-M_{h}=0$

(11)

If $\mathrm{H}$ is positive and too small, the term

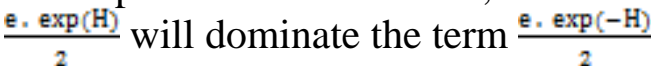
and $\mathrm{H}$

then $\frac{\Theta \text {, } \exp (H)}{2}-M_{h} \cong 0$ or $\exp (H)=\frac{M_{h}}{2}$, that is the initial guess can be suggested as $\mathrm{H}_{0}=\ln \left(\frac{\mathrm{M}_{\mathrm{h}}}{\mathrm{e}}\right)$

For a modification of eq. (12), consider

$\mathrm{H}_{0}=\ln \left(\frac{2 \mathrm{~N}_{\mathrm{h}}+\mathrm{ke}}{\epsilon}\right), \mathrm{K}>0$

In this paper, we will take the values of $\mathrm{k}=1.5$ and $\mathrm{k}=2$. 
That is the first guess hyperbolic eccentric anomaly is $\mathrm{H}_{0}=\ln \left(\frac{2 \mathrm{M}_{\mathrm{h}}}{\mathrm{e}}+1.5\right)$ and $\mathrm{H}_{0}=\ln \left(\frac{2 \mathrm{M}_{\mathrm{h}}}{\mathrm{e}}+2\right)$, where $\mathrm{e}$ is the eccentricity and $\mathrm{M}_{\mathrm{h}}$ is the hyperbolic mean anomaly.

\section{Results and Discussion:}

Now, we employ the new algorithms defined by Algorithm (1) and Algorithm (2) (called algo. (1) and algo. (2) respectively) to solve the hyperbolic orbit equation, eq. (1), with the values of $e$ and $\mathrm{M}_{\mathrm{h}}$ such that $1.5 \leq e \leq 6$ and $0.5 \leq \mathrm{M}_{\mathrm{h}} \leq 3$ with the grid size $\Delta \mathrm{M}_{\mathrm{h}}=\Delta \mathrm{e}=0.5$ and $1.5 \leq e \leq 6$, $4 \leq \mathrm{M}_{\mathrm{h}} \leq 6$ with the grid size $\Delta \mathrm{e}=0.5$ and $\Delta \mathrm{M}_{\mathrm{h}}=1$. The results are compared with the Newton's method (NM), and implicit method (IM) presented in [13]. Newton's method (NM) defined by

Table (1) approximate values of hyperbolic eccentric anomaly $H$ for $e \in[1,5,6]$ and $M_{h} \in[0.5,3]$

\begin{tabular}{|c|c|c|c|c|c|c|}
\hline \multirow{2}{*}{$e$} & \multicolumn{7}{|c|}{ M } \\
\cline { 2 - 8 } & $\mathbf{0 . 5}$ & $\mathbf{1}$ & $\mathbf{1 . 5}$ & $\mathbf{2}$ & $\mathbf{2 . 5}$ & \\
\hline 1.5 & 0.767343174954097 & 1.161635444504607 & 1.419318997767211 & 1.612685809758494 & 1.768471980642198 & 1.899455945779613 \\
\hline 2 & 0.465918338092022 & 0.814096796302133 & 1.068949515655137 & 1.266466394761583 & 1.427248348233055 & 1.562846184058930 \\
\hline 2.5 & 0.323849090576097 & 0.604253077612260 & 0.833482624172061 & 1.0214558377209285 & 1.178878455389913 & 1.313659736077374 \\
\hline 3 & 0.246255329197959 & 0.473210512943636 & 0.672297648451068 & 0.844160895220278 & 0.992920932830292 & 1.122965790420873 \\
\hline 3.5 & 0.198180254127233 & 0,386434195697187 & 0.558673705730567 & 0.713181111482953 & 0.850935018666102 & 0.973963134170166 \\
\hline 4 & 0.165655092505051 & 0.325620320153691 & 0.475792271167117 & 0.614197943662934 & 0.740568312317250 & 0.855618644559227 \\
\hline 4.5 & 0.142239842774321 & 0.250943771306711 & 0.413312072960204 & 0.527641782954010 & 0.6532599442666596 & 0.760231909836225 \\
\hline 5 & 0.124596711715797 & 0.246856484955990 & 0.364817047438061 & 0.477114133702127 & 0.583008513011944 & 0.682276119458112 \\
\hline 5.5 & 0.110833600247207 & 0.220046547437196 & 0.326223563606965 & 0.428293238691502 & 0.525571491411331 & 0.617726098649502 \\
\hline 6 & 0.099801092042564 & 0.198434206048714 & 0.294850971404480 & 0.388210290545513 & 0.477917546576672 & 0.563618464084191 \\
\hline
\end{tabular}

Table (2) approximate values of $H$ for $e \in[1.5,6]$ and $M_{h} \in[4,6]$

\begin{tabular}{|l|c|c|c|}
\hline \multirow{2}{*}{$\mathbf{e}$} & \multicolumn{3}{|c|}{$\mathbf{M}$} \\
\cline { 2 - 5 } & $\mathbf{4}$ & $\mathbf{5}$ & $\mathbf{6}$ \\
\hline 1.5 & 2.112790119048360 & 2.283768204998324 & 2.426944922150705 \\
\hline 2 & 1.783676134093071 & 1.960245368712180 & 2.107689797681256 \\
\hline 2.5 & 1.535524936197112 & 1.714045050249153 & 1.863443026888276 \\
\hline 3 & 1.340820381738082 & 1.518338458299501 & 1.667807145181898 \\
\hline 3.5 & 1.184306419638314 & 1.358533902255432 & 1.506547619688230 \\
\hline 4 & 1.056365694702679 & 1.225653846879397 & 1.371017590592114 \\
\hline 4.5 & 0.950407902936279 & 1.113677992516098 & 1.255502173232205 \\
\hline 5 & 0.861675658829969 & 1.018316168394280 & 1.155981761583699 \\
\hline 5.5 & 0.786623915954167 & 0.936378863250262 & 1.069494872123864 \\
\hline 6 & 0.722557799647903 & 0.865424444833936 & 0.993782991955256 \\
\hline
\end{tabular}

The number of iterations to 15 digit convergence, for various combinations
$\mathrm{H}_{\mathrm{n}+1}=\mathrm{H}_{\mathrm{n}}-\frac{\mathrm{f}\left(\mathrm{H}_{\mathrm{n}}\right)}{\mathrm{f}\left(\mathrm{H}_{\mathrm{n}}\right)}$

and Implicit method (IM) defined by [13]

$\mathrm{H}_{\mathrm{n}+1}=\mathrm{H}_{\mathrm{n}}-\frac{2 \mathrm{f}\left(\mathrm{H}_{\mathrm{n}}\right)}{\left[\mathrm{f}\left(\mathrm{H}_{\mathrm{n}+1}^{*}\right)+\mathrm{f}\left(\mathrm{H}_{\mathrm{n}}\right)\right]}$

where $f\left(H_{n+1}^{*}\right)=H_{n}-\frac{f\left(H_{n}\right)}{f\left(H_{n}\right)}$ and the starting value $\mathrm{H}_{0}$ is
i) $H_{0}=\ln \left(\frac{2 M_{h}}{e}+1.5\right)$
ii) $H_{0}=\ln \left(\frac{2 M_{h}}{\bullet}+2\right)$

disply in table (1) are the approximate values of hyperbolic eccentric anomaly $H$ for $e \in[1.5,6]$ and $M_{h} \in[0.5,3]$ with $\Delta \mathrm{M}_{\mathrm{h}}=\Delta \mathrm{e}=0.5$, while the approximate values of $H$ for $e \in[1.5,6]$ with $\Delta \mathrm{e}=0.5$ and $M_{h} \in[4,6]$ with $\Delta \mathrm{M}_{\mathrm{h}}=1$ are listed in table (2). 
are listed in tables (3) and (4) respectively, using Newton's method

(NM) and implicit method (IM) [13].

Table (3) number of iterations with $H_{0}=\ln \left(\frac{2 M_{h}}{e}+1.5\right)$; using (NM) and (IM) methods.

\begin{tabular}{|c|c|c|c|c|c|c|c|c|c|c|c|c|}
\hline \multirow{3}{*}{ e } & \multicolumn{12}{|c|}{$\mathbf{M}_{\mathrm{h}}$} \\
\hline & \multicolumn{2}{|c|}{0.5} & \multicolumn{2}{|c|}{1} & \multicolumn{2}{|c|}{1.5} & \multicolumn{2}{|c|}{2} & \multicolumn{2}{|c|}{2.5} & \multicolumn{2}{|c|}{3} \\
\hline & NM & IM & NM & IM & NM & IM & NM & IM & NM & IM & NM & IM \\
\hline 1.5 & 5 & 4 & 4 & 3 & 4 & 3 & 4 & 3 & 4 & 3 & 5 & 4 \\
\hline 2 & 5 & 4 & 4 & 3 & 4 & 3 & 4 & 3 & 5 & 4 & 5 & 4 \\
\hline 2.5 & 5 & 4 & 5 & 4 & 5 & 4 & 5 & 4 & 5 & 4 & 5 & 4 \\
\hline 3 & 5 & 4 & 5 & 4 & 5 & 4 & 5 & 4 & 5 & 4 & 5 & 4 \\
\hline 3.5 & 4 & 3 & 5 & 4 & 5 & 4 & 4 & 3 & 5 & 4 & 5 & 4 \\
\hline 4 & 5 & 4 & 5 & 4 & 5 & 4 & 5 & 4 & 5 & 4 & 5 & 4 \\
\hline 4.5 & 5 & 4 & 5 & 4 & 5 & 4 & 5 & 4 & 4 & 3 & 5 & 4 \\
\hline 5 & 5 & 4 & 5 & 4 & 5 & 4 & 5 & 4 & 5 & 4 & 5 & 4 \\
\hline 5.5 & 5 & 4 & 5 & 4 & 5 & 4 & 5 & 4 & 5 & 4 & 5 & 4 \\
\hline 6 & 4 & 3 & 5 & 4 & 5 & 4 & 5 & 4 & 5 & 4 & 5 & 4 \\
\hline
\end{tabular}

Table (4) number of iterations with $\mathrm{H}_{0}=\ln \left(\frac{2 \mathrm{M}_{\mathrm{h}}}{\mathrm{e}}+2\right)$; using (NM) and (IM) methods.

\begin{tabular}{|c|c|c|c|c|c|c|c|c|c|c|c|c|}
\hline \multirow{3}{*}{ e } & \multicolumn{12}{|c|}{$\mathbf{M}_{\mathrm{h}}$} \\
\hline & \multicolumn{2}{|c|}{0.5} & \multicolumn{2}{|c|}{1} & \multicolumn{2}{|c|}{1.5} & \multicolumn{2}{|c|}{2} & \multicolumn{2}{|c|}{2.5} & \multicolumn{2}{|c|}{3} \\
\hline & NM & IM & NM & IM & NM & IM & NM & IM & NM & IM & NM & IM \\
\hline 1.5 & 5 & 4 & 4 & 3 & 4 & 3 & 4 & 3 & 4 & 3 & 5 & 4 \\
\hline 2 & 5 & 4 & 4 & 3 & 4 & 3 & 4 & 3 & 5 & 4 & 5 & 4 \\
\hline 2.5 & 5 & 4 & 5 & 4 & 5 & 4 & 5 & 4 & 5 & 4 & 5 & 4 \\
\hline 3 & 5 & 4 & 5 & 4 & 5 & 4 & 5 & 4 & 5 & 4 & 5 & 4 \\
\hline 3.5 & 4 & 3 & 5 & 4 & 5 & 4 & 4 & 3 & 5 & 4 & 5 & 4 \\
\hline 4 & 5 & 4 & 5 & 4 & 5 & 4 & 5 & 4 & 5 & 4 & 5 & 4 \\
\hline 4.5 & 5 & 4 & 5 & 4 & 5 & 4 & 5 & 4 & 4 & 3 & 5 & 4 \\
\hline 5 & 5 & 4 & 5 & 4 & 5 & 4 & 5 & 4 & 5 & 4 & 5 & 4 \\
\hline 5.5 & 5 & 4 & 5 & 4 & 5 & 4 & 5 & 4 & 5 & 4 & 5 & 4 \\
\hline 6 & 4 & 3 & 5 & 4 & 5 & 4 & 5 & 4 & 5 & 4 & 5 & 4 \\
\hline 6 & 5 & 4 & 5 & 5 & 5 & 5 & 5 & 5 & 5 & 5 & 5 & 5 \\
\hline
\end{tabular}

The number of iterations to 15 digit convergence, for various combinations of $\left(e, M_{h}\right)$ when the first guess is $\mathrm{H}_{0}=\ln \left(\frac{2 \mathrm{M}_{\mathrm{h}}}{\mathrm{t}}+1.5\right)$ and $\mathrm{H}_{0}=\ln \left(\frac{2 \mathrm{Ml}_{\mathrm{h}}}{\mathrm{t}}+2\right)$ are listed in tables (3) and (4) respectively, using Algorithm (1) (Alg. (1)) and Algorithm (2) (Alg. (2)), present in this paper are listed in tables (5) and (6) respectively.

Table (5) number of iterations with $\mathrm{H}_{0}=\ln \left(\frac{2 \mathrm{M}_{\mathrm{h}}}{\mathrm{e}}+1.5\right)$; using Alg. (1) and Alg. (2) methods.

\begin{tabular}{|c|c|c|c|c|c|c|c|c|c|c|c|c|}
\hline \multirow{3}{*}{ e } & \multicolumn{12}{|c|}{$\mathrm{M}_{\mathrm{h}}$} \\
\hline & \multicolumn{2}{|c|}{0.5} & \multicolumn{2}{|c|}{1} & \multicolumn{2}{|c|}{1.5} & \multicolumn{2}{|c|}{2} & \multicolumn{2}{|c|}{2.5} & \multicolumn{2}{|c|}{3} \\
\hline & $\begin{array}{l}\text { Alg. } \\
\text { 1) }\end{array}$ & $\begin{array}{l}\text { Alg. } \\
\text { (2) }\end{array}$ & $\begin{array}{c}\text { Alg. } \\
\text { (1) }\end{array}$ & $\begin{array}{l}\text { Alg. } \\
\text { (2) }\end{array}$ & $\begin{array}{l}\text { Alg. } \\
\text { (1) }\end{array}$ & $\begin{array}{l}\text { Alg. } \\
\text { (2) }\end{array}$ & $\begin{array}{l}\text { Alg. } \\
\text { (1) }\end{array}$ & $\begin{array}{l}\text { Alg. } \\
\text { (2) }\end{array}$ & $\begin{array}{l}\text { Alg. } \\
\text { (1) }\end{array}$ & $\begin{array}{l}\text { Alg. } \\
\text { (2) }\end{array}$ & $\begin{array}{l}\text { Alg.( } \\
\text { 1) }\end{array}$ & $\begin{array}{l}\text { Alg. } \\
\text { (2) }\end{array}$ \\
\hline 1.5 & 3 & 2 & 3 & 2 & 3 & 2 & 3 & 2 & 3 & 2 & 3 & 2 \\
\hline 2 & 3 & 2 & 3 & 2 & 3 & 2 & 3 & 2 & 3 & 2 & 3 & 2 \\
\hline 2.5 & 3 & 2 & 3 & 2 & 3 & 2 & 3 & 2 & 3 & 2 & 3 & 2 \\
\hline 3 & 3 & 2 & 3 & 2 & 3 & 2 & 3 & 2 & 3 & 2 & 3 & 2 \\
\hline 3.5 & 3 & 2 & 3 & 2 & 3 & 2 & 3 & 2 & 3 & 2 & 3 & 2 \\
\hline 4 & 3 & 2 & 3 & 2 & 3 & 2 & 3 & 2 & 3 & 2 & 3 & 2 \\
\hline 4.5 & 3 & 2 & 3 & 2 & 3 & 2 & 3 & 2 & 3 & 2 & 3 & 2 \\
\hline 5 & 3 & 2 & 3 & 2 & 3 & 2 & 3 & 2 & 3 & 2 & 3 & 2 \\
\hline 5.5 & 3 & 2 & 3 & 2 & 3 & 2 & 3 & 2 & 3 & 2 & 3 & 2 \\
\hline 6 & 3 & 2 & 3 & 2 & 3 & 2 & 3 & 2 & 3 & 2 & 3 & 2 \\
\hline
\end{tabular}


Table (6) number of iterations with $H_{0}=\ln \left(\frac{2 M_{h}}{e}+2\right)$; using Alg. (1) and Alg. (2) methods.

\begin{tabular}{|c|c|c|c|c|c|c|c|c|c|c|c|c|}
\hline \multirow{3}{*}{ e } & \multicolumn{12}{|c|}{$\mathbf{M}_{\mathrm{h}}$} \\
\hline & \multicolumn{2}{|c|}{0.5} & \multicolumn{2}{|c|}{1} & \multicolumn{2}{|c|}{1.5} & \multicolumn{2}{|c|}{2} & \multicolumn{2}{|c|}{2.5} & \multicolumn{2}{|c|}{3} \\
\hline & $\begin{array}{c}\text { Alg.( } \\
\text { 1) }\end{array}$ & $\begin{array}{l}\text { Alg. } \\
\text { (2) }\end{array}$ & $\begin{array}{c}\text { Alg. } \\
\text { (1) }\end{array}$ & $\begin{array}{l}\text { Alg. } \\
\text { (2) }\end{array}$ & $\begin{array}{c}\text { Alg. } \\
\text { (1) }\end{array}$ & $\begin{array}{c}\text { Alg. } \\
\text { (2) }\end{array}$ & $\begin{array}{l}\text { Alg. } \\
\text { (1) }\end{array}$ & $\begin{array}{l}\text { Alg. } \\
\text { (2) }\end{array}$ & $\begin{array}{c}\text { Alg. } \\
\text { (1) }\end{array}$ & $\begin{array}{l}\text { Alg. } \\
\text { (2) }\end{array}$ & $\begin{array}{c}\text { Alg.( } \\
\text { 1) }\end{array}$ & $\begin{array}{l}\text { Alg. } \\
\text { (2) }\end{array}$ \\
\hline 1.5 & 3 & 2 & 3 & 2 & 3 & 2 & 3 & 2 & 3 & 2 & 3 & 2 \\
\hline 2 & 3 & 2 & 3 & 2 & 3 & 2 & 3 & 2 & 3 & 2 & 3 & 2 \\
\hline 2.5 & 3 & 2 & 3 & 2 & 3 & 2 & 3 & 2 & 3 & 2 & 3 & 2 \\
\hline 3 & 3 & 2 & 3 & 2 & 3 & 2 & 3 & 2 & 3 & 2 & 3 & 2 \\
\hline 3.5 & 3 & 2 & 3 & 2 & 3 & 2 & 3 & 2 & 3 & 2 & 3 & 2 \\
\hline 4 & 3 & 2 & 3 & 2 & 3 & 2 & 3 & 2 & 3 & 2 & 3 & 2 \\
\hline 4.5 & 3 & 2 & 3 & 2 & 3 & 2 & 3 & 2 & 3 & 2 & 3 & 2 \\
\hline 5 & 3 & 2 & 3 & 2 & 3 & 2 & 3 & 2 & 3 & 2 & 3 & 2 \\
\hline 5.5 & 3 & 2 & 3 & 2 & 3 & 2 & 3 & 2 & 3 & 2 & 3 & 2 \\
\hline 6 & 3 & 2 & 3 & 2 & 3 & 2 & 3 & 2 & 3 & 2 & 3 & 2 \\
\hline
\end{tabular}

The number of iterations to 15 digit convergence, for $e \in[1.5,6]$ with $\Delta \mathrm{e}=0.5$ and $M_{\mathrm{h}} \in[4,6]$ with $\Delta \mathrm{M}_{\mathrm{h}}=1$ are illustrated in table (7) with $\mathrm{H}_{0}=\ln \left(\frac{2 \mathrm{M}_{\mathrm{h}}}{\mathrm{f}}+2\right)$ using NM, IM, Alg. (1) and Alg. (2) .

Table (7) number of iterations with $H_{0}=\ln \left(\frac{2 M_{h}}{e}+2\right)$; for $e \in[1.5,6]$ and $M_{h} \in[4,6]$

\begin{tabular}{|c|c|c|c|c|c|c|c|c|c|c|c|c|}
\hline \multirow{3}{*}{ e } & \multicolumn{12}{|c|}{$\mathbf{M}_{\mathbf{h}}$} \\
\hline & \multicolumn{4}{|c|}{4} & \multicolumn{4}{|c|}{5} & \multicolumn{4}{|c|}{6} \\
\hline & NM & IM & Alg. (1) & Alg. (2) & NM & IM & Alg. (1) & Alg. (2) & NM & IM & Alg.(1) & Alg. (2) \\
\hline 1.5 & 5 & 4 & 3 & 2 & 6 & 4 & 3 & 2 & 5 & 4 & 3 & 2 \\
\hline 2 & 5 & 3 & 3 & 2 & 5 & 4 & 3 & 2 & 5 & 4 & 3 & 2 \\
\hline 2.5 & 5 & 4 & 3 & 2 & 5 & 4 & 3 & 2 & 6 & 4 & 3 & 2 \\
\hline 3 & 6 & 4 & 3 & 2 & 5 & 4 & 3 & 2 & 5 & 4 & 3 & 2 \\
\hline 3.5 & 6 & 4 & 3 & 2 & 6 & 4 & 3 & 2 & 5 & 4 & 3 & 2 \\
\hline 4 & 5 & 4 & 3 & 2 & 6 & 4 & 3 & 2 & 6 & 4 & 3 & 2 \\
\hline 4.5 & 5 & 4 & 3 & 2 & 6 & 4 & 3 & 2 & 6 & 4 & 3 & 2 \\
\hline 5 & 5 & 4 & 3 & 2 & 6 & 4 & 3 & 2 & 6 & 4 & 3 & 2 \\
\hline 5.5 & 6 & 4 & 3 & 2 & 5 & 4 & 3 & 2 & 6 & 4 & 3 & 2 \\
\hline 6 & 7 & 4 & 3 & 2 & 6 & 5 & 3 & 2 & 6 & 5 & 3 & 2 \\
\hline
\end{tabular}

Depending on the results of tables (2); will illustrate the relation between hyperbolic eccentric anomaly $\mathrm{H}$ and eccentricity $e$ when the values of hyperbolic mean anomaly $\mathrm{M}_{\mathrm{h}}=4,5,6$ by the Figures (1-3).

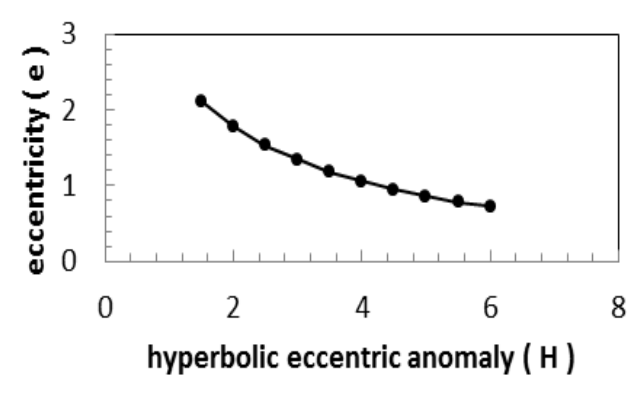

Fig. (1) the relation between e and $\mathrm{H}$ with $M_{h}=0.5$

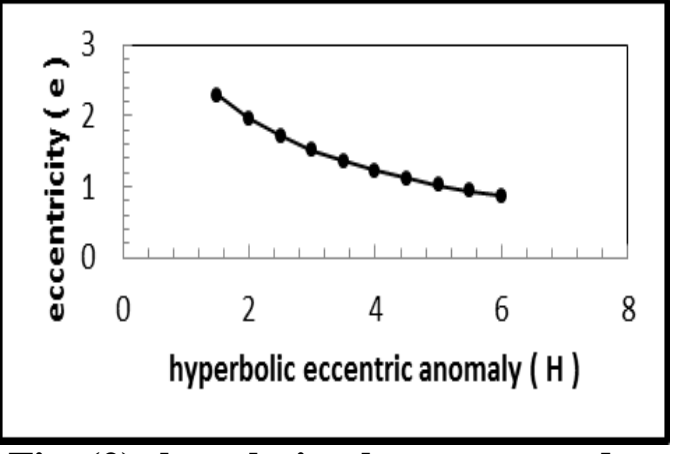

Fig. (2) the relation between e and $\mathrm{H}$ with $\mathrm{M}_{\mathrm{h}}=1$ 


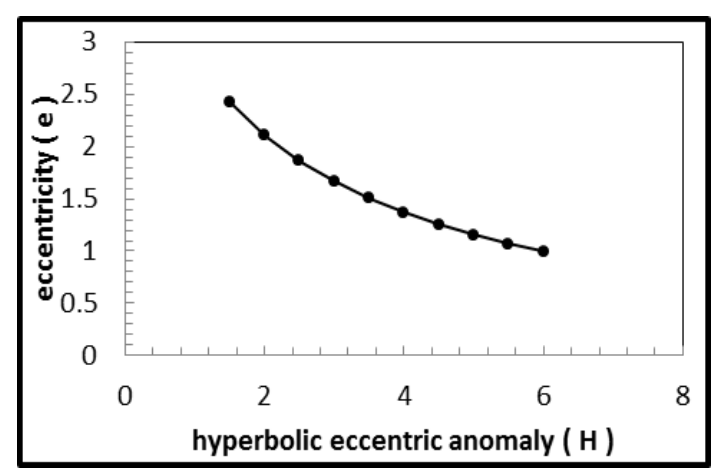

Fig. (3) the relation between e and $H$ with $M_{h}=1.5$

\section{Conclusions:}

The procedure were suggested depending on quadrature formula as corrector method and combining with Newton and Halley methods as predictor corrector methods to solve Kepler's equation for the hyperbolic case. The solution interval is $1.5 \leq e \leq 3$ and $0.5 \leq \mathrm{M}_{\mathrm{h}} \leq 6$. Numerical measurements showed that, the new algorithms are the fast as well as more efficient and perform better than classical Newton's method and many other methods. All numerical solutions in the illustrations were found using the first guesses hyperbolic eccentric anomaly either $\quad H_{0}=\ln \left(\frac{2 M_{h}}{6}+2\right)$ or $H_{0}=\ln \left(\frac{2 M_{h}}{g}+1.5\right)$, writing the hyperbolic orbit equation as $f(H)=0$, iterations were stopped when $\left|H_{n+1}-H_{n}\right|<10^{-15}$.

\section{References:}

1. Westpfahl D. J., 2011. "Orbital Mechanics Course Notes", New Mexico Institute of Mining and Technology, Lecture Notes, March 31.

2. Sharaf M. A. and Sharaf A. A., 2003, "Celestial Mechanics and Dynamical Astronomy", Vol. 86, No. 4, SpringerLink, August, Avialable at: IVSL.org.

3. Collins G. W.,2007, "The foundations of Celestial Mechanics", The pachart Foundation DBG Pachart Publishing House and required by
Permission, Case Western Reserve University, 2-4,

4. Filzpatrick R., 2012, "An introduction to Celestial Mechanics", University of Texas, Austin, June 25.

5. Burkardt T. M., and Danby J. M., 1983, "The solution of Kepler's Equation, II Celestial Mechanics", Celestial Mechanics Journal, Vol. 31, November, pp. 317-328, Avialable at: IVSL.org.

6. Gooding R. H. and Odell A. W., 1989, "The hyperbolic Kepler's Equation and the elliptic Equation", Royal Aerospace Establishment Farnborough, (United Kingdom), July 4.

7. Sharaf M. A. and Banajh M. A.,2007, "Homotopy Continuation Method of arbitrary order of Convergence for Solving The hyperbolic form of Kepler's Equation", Astrophys And Astr J, 28,1,9-16.

8. Sharaf M. A. and Selim H. H., 2006,"Homotopy Continuation Method for Solving Hyperbolic Form of Kepler's Equation", Contributions of the Astronomical Observatory Skalnaté Pleso,36,2,71-76.

9. Fukushima T., 1997, "A method Solving Kepler's Equation for Hyperbolic Case", Celest Mech and Dyn Astr ,68, 2, 121-137. Avialable from: IVSL.org.

10. Serafin R. A., 2002,"On Solving Kepler's Equation for Nearly Rectilinear Hyperbolic Orbits", Celest Mech and Dyn Astr, 82, 4, pp: 363-373. Avialable from: IVSL.org.

11. Guliyev A. S. and Daolashov A. S.,2010, "On Hyperbolic Comets", Proceedings of the International Astronomical Union Journal, 5, 
S263, 81-84. April 6, Avialable on: IVSL.org.

12. James J. D., 2007, Set 1: "Introduction to the N-body Problem", Celestial Mechanics Notes, January 3,. Avialable at: IVSL.org.
13. Rasheed M. S., 2012, "Comparison of Starting Values for Implicit Iterative Solutions to Hyperbolic Orbits Equation", IJSWS, 2, 1, 6571.

حل مسار القطع الزائد بأستخدام خوارزميات التخمين - التصحيح التربيعية الجديدة

\section{محد سهام رشيل**}

*الجامعة التكنولوجية، قسم العلوم التطبيقية،الجامعة التكنولوجيةـ ص.ب: 35317 - بغداد- العراق.

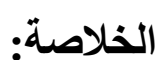

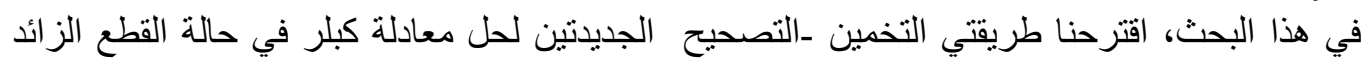

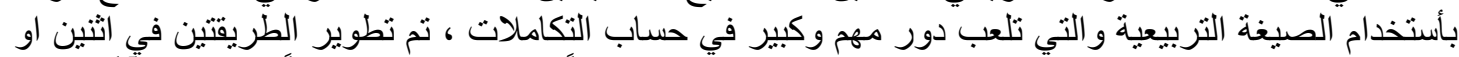

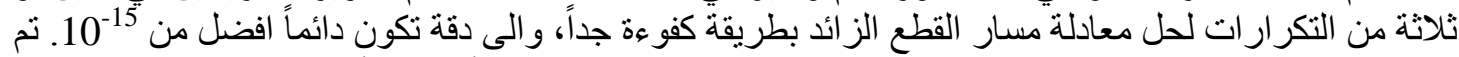

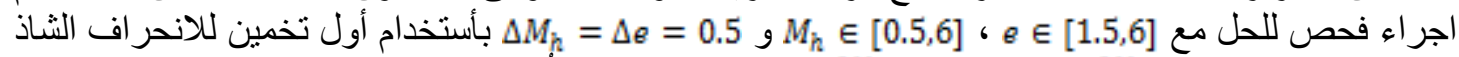

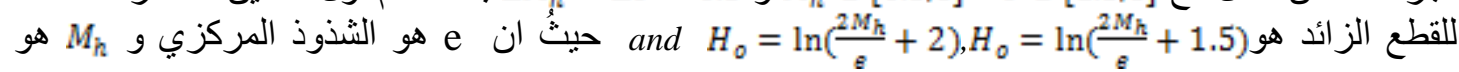
الانحر اف المتوسط للقطع الز ائد. 